\title{
REALISMOS JURÍDICOS, DIREITO EM AÇÃO E O ESTUDO EMPÍRICO DAS INSTITUIÇÕES
}

\author{
CARLOS BOLONHA \\ PEDRO RUBIM BORGES FORTES \\ DANIEL DE SOUZA LUCAS
}

A perspectiva realista do direito importa em uma visão empiricamente orientada para o desenvolvimento das instituições a partir da análise da evolução histórica, bem como da reflexividade e interação recíproca entre relações jurídicas e sociais. ${ }^{1}$ No cenário contemporâneo brasileiro, a investigação do realismo institucional pressupõe o estudo profundo do papel do Supremo Tribunal Federal (STF), merecendo o exame detalhado das relações políticas em que o Tribunal está inserido ${ }^{2}$ e o mapeamento existencial das emoções e sentimentos que permeiam o Supremo. ${ }^{3} \mathrm{O}$ conhecimento sobre o STF implica não somente a descrição jornalística de sua estrutura organizacional interna, ${ }^{4}$ mas também análises elaboradas a partir de estudos qualitativos de casos empíricos e de análises quantitativas a partir de padrões estatísticos do seu processo decisório. O presente número apresenta um dossiê organizado pelo Professor do INSPER, Diego Werneck Arguelhes, com uma proposta de uma análise do STF a partir do seu funcionamento organizacional, processo decisório, limites políticos, seleção de casos, agendamento de pauta e sua capacidade institucional. Em seu texto de apresentação do dossiê, Diego Werneck se refere a uma virada realista nas pesquisas realizadas sobre o Supremo e seus Ministros na última década, explicando que o fio condutor dos textos consiste justamente no foco da estrutura da corte e de suas implicações para a nossa reflexão sobre o STF.

O realismo jurídico possui uma tradição importante e merece a posição de destaque que tem obtido recentemente na academia jurídica brasileira. O ponto de partida para o estudo do realismo costuma ser o movimento liderado a partir de 1930 nos Estados Unidos pelo professor Karl Llewellyn, com o foco de atenção no direito em ação e no projeto de descrição do que é observado. ${ }^{5}$ Além de trabalhos

\footnotetext{
${ }^{1}$ TAMANAHA, Brian. A Realistic Theory of Law. Cambridge: Cambridge University Press, 2017, p. 1-3.

2 VIEIRA, Oscar Vilhena. A Batalha dos Poderes: Da Transição Democrática ao Mal-Estar Constitucional. São Paulo: Companhia das Letras, 2018.

${ }^{3}$ FALCÃO, Joaquim. Interpretação Constitucional e Insegurança Jurídica. In: LEAL, Fernando (Org.). Constitucionalismo de Realidade: Democracia, Direitos e Instituições. Belo Horizonte: Fórum, 2019, p. 34.

${ }^{4}$ RECONDO, Felipe; WEBER, Luiz. Os Onze: O STF, Seus Bastidores e Suas Crises. São Paulo: Companhia das Letras, 2019.

5 TWINING, William. Karl Llewellyn and the Realism Movement. 2. ed. Cambridge: Cambridge University Press, 2012, p. 74.
} 
seminais sobre as bases teóricas do realismo jurídico, ${ }^{6}$ Karl Llewellyn produziu estudos pioneiros sobre os efeitos das instituições jurídicas na economia ${ }^{7}$ e sobre a constituição como uma instituição. ${ }^{8}$ Além desse movimento específico na academia jurídica, é possível identificar uma origem ainda mais remota do realismo institucional na filosofia política, na medida em que as ideias sobre a relevância das regras do jogo institucional para o desenvolvimento econômico e da estrutura da constituição como uma instituição podem ser encontradas nas obras de expoentes do iluminismo escocês como Adam Smith e David Hume respectivamente. ${ }^{9}$ Além disso, na tradição da filosofia política da Europa continental, existe uma linhagem de teorias políticas realistas com análise empírica e pragmática das dinâmicas de poder e das relações concretas de domínio a partir das obras clássicas de Niccolò Machiavelli. ${ }^{10}$ Se a origem do realismo pode ser identificada nos primórdios da filosofia política moderna e justamente no pensador que cunhou o conceito de Estado, seu desenvolvimento tem se caracterizado pela interdisciplinaridade e por perspectivas relativas às influências recíprocas entre o direito, a economia, a sociologia e outras disciplinas afins.

$\mathrm{Na}$ academia norte-americana atualmente, existe um movimento de ressignificação do campo da pesquisa sócio-jurídica realista e que se apresenta como sendo o novo realismo jurídico ("New Legal Realism"). ${ }^{11}$ Explicando em que consiste o novo realismo jurídico, Michael Cann explica que se trata de uma defesa de pesquisas teoricamente orientadas sobre o direito em ação ("law in action") que valoriza métodos qualitativos, quantitativos e experimentais de pesquisa. ${ }^{12} \mathrm{~A}$ aspiração desse movimento é de reapresentar as descobertas inovadoras da pesquisa sóciojurídica, amplificar seu significado, revitalizar seu impacto para a

${ }^{6}$ LLEWELLYN, Karl N. A realistic jurisprudence--the next step. Columbia Law Review, v. 30, 1930, p. 431; LLEWELLYN, Karl N. Some realism about realism: Responding to Dean Pound. Harvard Law Review, v. 44, n. 8, 1931, p. 1222-1264; LLEWELLYN, Karl N. The normative, the legal, and the law-jobs: the problem of juristic method. The Yale Law Journal, v. 49, n. 8, 1940, p. 1355-1400.

${ }^{7}$ LLEWELLYN, Karl N. The effect of legal institutions upon economics. The American Economic Review, v. 15, n. 4, 1925, p. 665-683.

${ }^{8}$ LLEWELLYN, Karl Nickerson. The Constitution as an institution. Columbia Law Review, v. 34, n. 1, 1934, p. 1-40.

9 TAMANAHA, Brian. A Realistic Theory of Law. Cambridge: Cambridge University Press, 2017, p. 4-8; SMITH, Adam. Wealth of Nations. Ware: Wordsworth, Classics, 2012, p. 708-721; HUME, David. Essays: Moral, Political and Literary. New York: Wallachia, 2015.

${ }^{10}$ BOBBIO, Norberto. Teoria Geral da Política: A Filosofia Política e as Lições dos Clássicos. Rio de Janeiro: Campus, 2000, p. 115-117; MACHIAVELLI, Niccolò. The Discourses. London: Penguin, 2003; MAQUIAVEL, Nicolau. O Príncipe. Porto Alegre: L\&PM, 2019.

${ }^{11}$ MERTZ, Elizabeth; MACAULAY, Stewart; MITCHELL, Thomas W. The New Legal Realism: Translating Law-and-Society for Today's Legal Practice (v. 1). Cambridge: Cambridge University Press, 2016.

${ }^{12}$ CANN, Michael. Preface. In: MERTZ, Elizabeth; MACAULAY, Stewart; MITCHELL, Thomas W. The New Legal Realism: Translating Law-and-Society for Today's Legal Practice (v. 1). Cambridge: Cambridge University Press, 2016, p. xiv. 
pesquisa e o ensino jurídico. ${ }^{13}$ Explicando o débito que o novo realismo possui com relação aos realistas jurídicos originais, Elizabeth Mertz se refere a mudança de consciência dos juristas e a reflexão sobre como o contexto social afeta a entrega do direito concreto e também como as decisões judiciais são influenciadas pelo mundo real além da doutrina e da jurisprudência. ${ }^{14} \mathrm{~A}$ seu turno, o novo realismo jurídico possui a pretensão de gerar uma forma de conhecimento jurídico genuinamente interdisciplinar com inspiração também nas pesquisas desenvolvidas pelo movimento "Direito e Sociedade" ("Law and Society Movement"). ${ }^{15}$

No Reino Unido, o Novo Realismo Jurídico tem sido representado pelo Movimento do Direito em Contexto ("Law in Context Movement") promovido pelo Professor William Twining, ex-aluno de Karl Llewellyn, e um pioneiro na difusão de ideias realistas na teoria do direito naquele país. ${ }^{16}$ Suas dez teses sobre o realismo jurídico e teoria do direito são fonte relevante para o debate sobre o tema, especialmente sobre sua missão para o avanço e difusão do conhecimento teórico e prático do direito, da teoria do direito, das ideologias e dos fatos sociais relativos ao direito. ${ }^{17}$ Além de alertar que o realismo nunca foi uma perspectiva exclusiva dos estadunidenses e de recomendar uma emancipação dos novos realistas daqueles debates históricos do Realismo Jurídico Americano ("American Legal Realism"), Twining considera que uma variedade de abordagens e conceitos sobrepostos de pesquisa jurídica interdisciplinar são relevantes para a visão realista independentemente do rótulo ou termo conceitual específico. ${ }^{18}$ Nesse contexto, o Novo Realismo Jurídico se apresenta como um movimento destinado a integrar estudos jurídicos empíricos de modo concreto na prática jurídica, educação jurídica e pesquisa para inclusive aproximar a advocacia da abordagem empírica do

\footnotetext{
${ }^{13}$ Idem, p. xiv-xv.

${ }^{14}$ MERTZ, Elisabeth. New Legal Realism: Law and Social Science in the New Millennium. MERTZ, Elizabeth; MACAULAY, Stewart; MITCHELL, Thomas W. (Eds.). The New Legal Realism: Translating Law-and-Society for Today's Legal Practice (v. 1). Cambridge: Cambridge University Press, 2016, p. 2.

${ }^{15}$ Idem, p. 4-5. Sobre o Movimento Direito e Sociedade ver FRIEDMAN, Lawrence M. The law and society movement. Stanford Law Review, 1986, p. 763-780 e FORTES, Pedro Rubim Borges. O Expositor da Cultura Jurídica e da História do Direito: Pioneirismo e Impacto de Lawrence Friedman. Passagens: Revista Internacional de História Política e Cultura Jurídica, v. 11, n. 1, 2019, p. 24-40.

16 TWINING, William. Jurist in Context: A Memoir. Cambridge: Cambridge University Press, 2019; FORTES, Pedro Rubim Borges. AN EXPLORER OF LEGAL BORDERLANDS: A REVIEW OF WILLIAM TWINING'S JURIST IN CONTEXT, A MEMOIR. REI-Revista Estudos Institucionais, v. 5, n. 2, 2019, p. 777-790.

17 TWINING, William. Legal Realism and Jurisprudence: Ten Theses. In: MERTZ, Elizabeth; MACAULAY, Stewart; MITCHELL, Thomas W. (Eds.). The New Legal Realism: Translating Lawand-Society for Today's Legal Practice (v. 1). Cambridge: Cambridge University Press, 2016, p. 123-128.

18 Idem, p. 128-130.
} 
direito. ${ }^{19} \mathrm{O}$ realismo pode contribuir para a teoria geral e especial do direito, podendo ser entendido como relevante (versão fraca), parte integral (versão moderada) ou essencial (versão forte) para a compreensão do fenômeno jurídico. ${ }^{20}$ Em conclusão, Twining considera que a globalização e o direito transnacional apresentam os maiores desafios para o realismo jurídico, especialmente pela dificuldade em se desenvolver generalizações baseadas em evidências sobre o direito através do globo. ${ }^{21}$

Uma vertente relevante do realismo é a decorrente de uma virada naturalista a partir da filosofia de Willard Van Orman Quine e que foi desenvolvida por Brian Leiter no já clássico livro Naturalizing Jurisprudence. ${ }^{22} \mathrm{O}$ renomado Professor da Universidade de Chicago retoma o tema através de um ensaio original em que apresenta uma análise programática sobre como deve ser uma teoria realista do direito. Brian Leiter esclarece que realistas pretendem descrever o fenômeno do direito e as instituições jurídicas como eles realmente são sem quaisquer ilusões moralistas ou românticas. ${ }^{23} \mathrm{~A}$ seu turno, os naturalistas estão comprometidos a descrever e explicar a realidade apenas a partir de mecanismos e entidades que podem ser explicados através dos métodos bem sucedidos das ciências empíricas. ${ }^{24}$ Um importante aspecto do naturalismo é que retira o apelo de fatos normativos, que não possuem qualquer papel nos paradigmas explicativos bem sucedidos de qualquer disciplina, sendo certo que a ausência de fatos objetivos sobre valores morais é fatal para as teorias do direito Dworkinianas e jusnaturalistas. ${ }^{25} \mathrm{Na}$ análise programática da teoria realista do direito, Brian Leiter preconiza que se deve ser realista sobre o papel limitado do judiciário sobre a vida do direito em sociedade, sobre os limites da aplicação do direito, práticas diferenciadas de aplicação conforme as partes e a influência das razões jurídicas apresentadas. ${ }^{26} \mathrm{~A}$ discussão sobre o fundamento sociológico da legitimidade do direito com base na extensão fática das atitudes e práticas dos agentes públicos nas diversas jurisdições aproxima o realismo jurídico do positivismo jurídico de H.L.A. Hart e sua famosa regra de reconhecimento, apesar do eminente Professor da Universidade de Oxford ter sido um crítico dos realistas jurídicos estadunidenses e dos escandinavos. ${ }^{27}$. Aliás, o impulso naturalista de Hart fica evidenciado pela ausência de quaisquer referências

\footnotetext{
${ }^{19}$ Idem, p. 131-132.

${ }^{20}$ Idem, p. 132-138.

${ }^{21}$ Idem, p. 139-140.

${ }^{22}$ LEITER, Brian. Naturalizing Jurisprudence: Essays on American Legal Realism and Naturalism in Legal Philosophy. Oxford: Oxford University Press, 2007.

${ }^{23}$ LEITER, Brian. What is a Realist Theory of Law? REI-Revista Estudos Institucionais, v. 6, n. 1, 2020.

${ }^{24}$ Idem, 2-3.

${ }^{25}$ Idem, $4-5$.

${ }^{26}$ Idem, 5-6.

${ }^{27}$ Idem, 7-8. HART, H. L. A. The concept of law. Oxford: Oxford University Press, 2012; HART, H. L. A. Essays in jurisprudence and philosophy. OUP Oxford, 1983.
} 
a fatos normativos na sua teoria do direito em contraste com o realismo moral de Joseph Raz. ${ }^{28}$ A publicação do artigo original inédito do Professor da Cadeira Karl Llewellyn de Teoria do Direito da Chicago Law School pela REI-Revista Estudos Institucionais serve para uma reflexão sobre os variados realismos jurídicos, seja o movimento clássico dos anos 1930 ou o contemporâneo Novo Realismo Jurídico, seja o positivismo jurídico ou o naturalismo, seja inspirado pela filosofia política moderna ou pelo neoinstitucionalismo econômico.

Quanto à relevância do realismo para a teoria institucional, o estudo empírico das instituições se desenvolveu bastante com base na metodologia de pesquisa de Max Weber, em especial seu método para "a construção de um curso de ação puramente racional em certos casos que proporcionam ao sociólogo um tipo (tipo ideal) que possui o mérito da clareza de compreensão e falta de ambiguidade" ${ }^{29}$ Sua iniciativa de abandonar a prática de tratar coletividades sociais como se fossem pessoas individuais alterou o foco em uma análise artificial da suposta atuação da pessoa jurídica para uma investigação sobre como os atores individuais orientam sua ação. ${ }^{30}$ Ao invés de antropomorfizar o Estado, a análise da ação do rei, do agente público e do procurador permite ao sociólogo formular tipos ideais puros correspondentes a cada forma de ação, de maneira a estabelecer uma diferenciação teórica e um significado preciso para cada termo. ${ }^{31} \mathrm{Na}$ esteira da ciência da realidade Weberiana, Hermann Heller articulou sua teoria realista do Estado com foco na conduta real do homem e nos objetivos propostos. ${ }^{32}$ Sua teoria do Estado constitui, assim, uma ciência sociológica da realidade que se propõe a compreendêlo e explicá-lo causalmente através da interpretação da conexão de atividade histórico-social. ${ }^{33}$ Seu realismo o contrapõe ao positivismo jurídico Kelseniano, na medida em que Hermann Heller considera paradoxal a tentativa de construir uma teoria do Estado sem o Estado, eis que a pretendida emancipação da teoria de todo o seu caráter político esvaziaria o conteúdo estatal e, sem deixá-lo livre das considerações valorativas, o privaria de seu valor. ${ }^{34}$ Também os tipos ideais Weberianos lhe parecem insuficientes, na medida em que não corresponderiam a nenhuma unidade real, mas a uma ficção ou síntese mental do estudioso. ${ }^{35}$ Nesse sentido, compete à teoria institucional sofisticar conceitos e metodologias

${ }^{28}$ LEITER, Brian. What is a Realist Theory of Law? REI-Revista Estudos Institucionais, v. 6, n. 1, 2020.

${ }^{29}$ WEBER, Max. Economy and Society: An Outline of Interpretive Sociology (v. 1). Berkeley: University of California Press, 1978, p. 6.

${ }^{30}$ Idem, p. 13-14.

${ }^{31}$ Idem, p. 18-20.

${ }^{32}$ HELLER, Hermann. Teoría del Estado. México: Fondo de Cultura Económica, 2002, p. 70.

${ }^{33}$ Idem, p. 76.

${ }^{34}$ Idem, p. 84-85.

${ }^{35}$ Idem, p. 93. 
adequadas para as relevantes questões relativas à dinâmica do poder político e ao papel das instituições no constitucionalismo contemporâneo. ${ }^{36}$

Ao longo dos últimos cinco anos, a REI-Revista de Estudos Institucionais tem estimulado o desenvolvimento da teoria institucional, inclusive sob a perspectiva do realismo jurídico, do direito em ação e do estudo empírico das instituições. No caso do presente número, além do dossiê realista sobre o STF e do artigo internacional de Brian Leiter sobre a teoria realista do direito, publicamos uma série de cinco artigos nacionais com contribuições relevantes e originais para essa literatura. Francisco Geraldo Matos Santos e Urá Lobato Martins adotaram métodos da sociologia e do neoinstitucionalismo para refletir sobre o comportamento de atores institucionais e instituições no exame da mudança jurisprudencial da Suprema Corte sobre a nomeação em concursos públicos. ${ }^{37}$ José Mário Wanderley Gomes Neto desenvolveu modelos aplicados para interpretação de dados empíricos relativos a variáveis para a compreensão do processo decisório dos juízes a partir de questões que afetam o processo deliberativo, políticas públicas e instituições representativas, de maneira a discutir o comportamento judicial com base em referências a categorias jurídicas, características do julgador e influência de outros atores ou fatores externos..$^{38}$ Por sua vez, Simone Bento Martins Cirilo, Giovani Clark e Leonardo Alves Corrêa adotaram fontes eminentemente documentais e uma metodologia de análise de regime de incentivos econômicos desenho institucional de normas premiais - para traçar uma história dos períodos de desenvolvimento de política industrial no setor automobilístico brasileiro ao longo das últimas três décadas. ${ }^{39}$ A seu turno, Natália Lucero Frias Tavares, Rodrigo Grazinoli Garrido e Antonio Eduardo Ramires Santoro analisam as políticas públicas de saúde para as pessoas presas no Estado do Rio de Janeiro a partir das medidas mitigatórias adotadas e do potencial impacto da ausência de uma política de saúde específica para o cárcere. ${ }^{40}$ Finalmente, Chiara Spadaccini de

36 SABADELL, Ana Lucia, Prefácio. BOLONHA, Carlos; BONIZZATO, Luigi; MAIA, Fabiana (Orgs.). Teoria Institucional e Constitucionalismo Contemporâneo. Curitiba, Juruá, 2016, p. 9.

37 SANTOS, Francisco Geraldo Matos; MARTINS, Urá Lobato. A Suprema Corte e a Mudança Jurisprudencial acerca do Direito à Nomeação em Concurso Público: Entre A Sociologia Política e a Vertente Neoinstitucionalista. REI-Revista Estudos Institucionais, v. 6, n. 1, 2020, p. 207-227.

38 GOMES NETO, José Mário Wanderley. Como Decidem os Juízes? Comparando os Modelos Formais Explicativos do Comportamento Judicial. REI-Revista Estudos Institucionais, v. 6, n. 1, 2020, p. 228-255.

${ }_{39}$ CIRILO, Simone Bento Martins; CLARK, Giovani; CORRÊA, Leonardo Alves. O Desenho Institucional das Políticas Industriais: Incentivos Fiscais Concedidos ao Setor Automobiliístico e suas Contrapartidas. REI-Revista Estudos Institucionais, v. 6, n. 1, 2020, p. 256-276.

${ }^{40}$ TAVARES, Natália Lucero Frias, GARRIDO, Rodrigo Grazinoli e SANTORO, Antonio Eduardo Ramires. Política de Saúde no Cárcere Fluminense: Impactos da Pandemia de COVID-19. REIRevista Estudos Institucionais, v. 6, n. 1, 2020, p. 277-300. 
Teffé e Felipe Medon discutem o regime de responsabilidade civil nas decisões empresariais com base em inteligência artificial. ${ }^{41}$

Além da ponte aérea acadêmica com o dossiê organizado pelo renomado Professor do INSPER com a participação de colaboradores da USP, FGV Direito SP, UFSCAR, INSPER e FGV Direito Rio, mantemos a tradição de representatividade regional ampla da Faculdade Nacional de Direito com valiosas colaborações de Professores da Regiões Norte e Nordeste, além do Sudeste. A Colaboração internacional desse número da REI consiste no artigo original e inédito do Professor da Universidade de Chicago, Brian Leiter, sobre o que é uma teoria jurídica realista. Além da profundidade dos realismos jurídicos desse número, a relevância dos artigos decorre do tratamento original de temas contemporâneos importantes para o Estado Democrático Brasileiro no plano institucional, tais como a produção industrial, a regulação da inteligência artificial, o processo decisório dos juízes, medidas sanitárias de combate à COVID-19 e a estrutura institucional do STF. Além dessa apresentação geral, a apresentação especial do dossiê “O Desenho do STF para além da Conjuntura" foi feita pelo Professor Diego Werneck Arguelhes.

Estamos honrados em iniciar este sexto volume da REI, que apresenta uma variedade de artigos de alto nível de discussão relacionados à nossa linha editorial. Divirtam-se!

${ }^{41}$ TEFFÉ, Chiara Spadaccini de; MEDON, Felipe. Responsabilidade Civil e Regulação de Novas Tecnologias: Questões acerca da Utilização de Inteligência Artificial na Tomada de Decisões Empresariais. REI-Revista Estudos Institucionais, v. 6, n. 1, 2020, p. 301-ss. 